\title{
PRODUÇÃO DA PIMENTA-DO-REINO DO BRASIL E ESTADO DO PARÁ ENTRE OS ANOS DE 2008 A 2017
}

\section{Waldenice Leite Pinheiro' ${ }^{1}$ Agnes de Souza Costa ${ }^{2}$}

${ }^{1}$ Licenciada em História - UVA, graduanda em Engenharia Agrícola - UFRA, especialista em Proteção de Plantas - UFV, mestranda em Agriculturas Amazônicas - UFPA, Tomé-Açu, PA, ${ }^{2}$ Engenheira de produção e especialista em Gestão Empresarial, FMS, Tomé-Açu, PA.

\section{DOI: 10.47094/ICONNECA.2021/16}

\section{RESUMO}

O estado do Pará se manteve como o maior produtor de pimenta-do-reino do Brasil por décadas, inclusive se tornando o maior exportador nacional. A posição de maior produtor se manteve até o ano de 2017, passando a posição no ano seguinte para o estado do Espírito Santo. A pesquisa classificase como descritiva, no qual analisa área destinada à colheita, área colhida e quantidade produzida da pimenta-do-reino através da análise de dados quantitativos. O trabalho objetivou analisar a produção da pimenta-do-reino no âmbito estadual em comparativo com a produção nacional, no período de 2009 a 2017. Foi realizada pesquisa bibliográfica sobre o histórico da produção da pimenta-do-reino no Pará e no Brasil, a fim de embasar os resultados encontrados.

Conclui-se que mesmo estado do Pará se destacando pela utilização de sistemas agroflorestais, ainda precisa buscar meios para melhorar a produtividade.

PALAVRAS-CHAVE: Agrofloresta. Produtividade. Pipericultura.

ÁREA TEMÁTICA: Outros.

\section{INTRODUÇÃO}

A pimenta-do-reino (Piper nigrun) é uma espécie perene, arbustiva, trepadeira, pertencente à família Piperácea, originária da Índia e que foi introduzida no Brasil na década de 1930 por colonos japoneses.

Na década de 1980, o Brasil alcançou o título de maior produtor mundial dessa cultura, e em 1990 decaiu a produção em função Fusarium solani f. sp. (CARNEIRO JÚNIOR, et al., 2017), uma doença de difícil controle e que acarreta em prejuízos inestimáveis a produção devido a morte precoce dos pimentais (GAIA et al., 2007; GOMES FILHO; SANTOS; AMORIM, 2020). 
O Brasil se mantém entre os principais produtores e exportadores dessa especiaria no mundo (SILVA et al., 2016). Entretanto, Filgueiras, Homma e Santos (2009) avaliaram no período de 1990 a 2007, que o menor registro nacional de área colhida ocorreu em 1998, onde o Brasil colheu apenas 11.175 hectares de área plantada. Nesse mesmo período a área colhida do estado do Pará foi de 8.828 hectares, uma representatividade de 79\% comparada à área colhida no Brasil. Em 2007 a participação paraense foi de 86\% com um total de 27.995 (ha) (FIGUEIRAS; HOMMA; SANTOS, 2009).

Ainda segundo Filgueiras, Homma e Santos (2009), o plantio de pimenta passou por um período de desestímulo decorrentes das flutuações de preço, entretanto, voltou a se firmar como importante produto na economia paraense, sendo um dos principais componentes iniciais na formação dos Sistemas Agroflorestais.

A especiaria exerce um papel significativo como geradora de emprego e renda, possibilitando oportunidades de negócio para produtores e agroindústrias. A pipericultura possui relevância no agronegócio paraense, obtendo destaque nas exportações agrícolas e na ocupação de mão de obra no meio agrário (CARNEIRO JÚNIOR et al., 2017).

Na safra 2012/2013 a área colhida teve uma variação negativa de 7,15\%, contudo, foi o segundo produto agrícola de maior valor exportado pelo estado do Pará no ano de 2013, superando apenas a soja (FAPESPA, 2015). Houve uma queda de produção substancial a partir do ano de 2018 e o Pará se configura como o segundo maior produtor nacional, perdendo espaço na produção para o Estado do Espírito Santo (IBGE, 2019).

Frente ao cenário de importância socioeconômica da pipericultura para o Estado do Pará e como uma importante atividade de desenvolvimento rural, o trabalho objetivou analisar a produção da pimenta-do-reino no âmbito estadual em comparativo com a produção nacional, no período de 2009 a 2017.

\section{METODOLOGIA}

A presente pesquisa classifica-se como descritiva, que segundo Gil (2018), pode ser construída com o intuito de identificar prováveis relações entre variáveis. No caso da pesquisa, a relação entre área destinada à colheita, área colhida e quantidade produzida da pimenta-do-reino.

A pesquisa utilizou referências bibliográficas de livros, artigos a fim de dar apoio e embasamento ao que se pretendia estudar. "A principal vantagem da pesquisa bibliográfica é o fato de permitir ao investigador a cobertura de uma gama de fenômenos muito mais ampla do que aquela que poderia pesquisar diretamente" (GIL, 2018, p.7).

Também foi realizado um levantamento de informações sobre produção da Pimenta-do-reino no Brasil e no estado do Pará, assim como identificação dos munícipios paraenses com as maiores produções da pimenta-do-reino através do Sistema IBGE de Recuperação Automática (SIDRA). 
A definição dos objetivos da pesquisa é quantitativa, de acordo com Gil (2018). "Os resultados, por sua vez, são analisados mediante a adoção de procedimentos de estatística descritiva ou inferencial, de acordo com os propósitos da pesquisa, que pode ser descritiva" (GIL, 2018, p.147).

\section{RESULTADOS E DISCUSSÃO}

O Brasil é um dos maiores exportadores de pimenta-do-reino do mundo. De acordo com o IBGE (2017) a área destinada à colheita e área colhida em dez anos revelam grandes oscilações, uma média de 23566.4 (ha). Na figura (1) pode ser observado que essas duas variáveis praticamente não tiveram variação em cada ano analisado. O ano de 2013 obteve menor área destinada a colheita como também de área colhida, um total de 18474 e 18472 de hectares, respectivamente.

Figura 1: Evolução da área destinada a colheita, área colhida e produção nacional, 2008-2017.

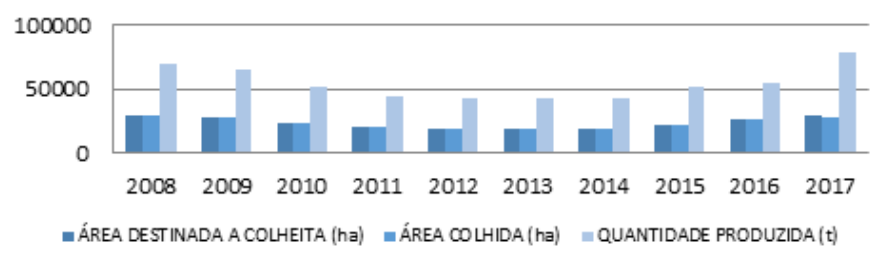

Fonte: Adaptado do IBGE (2018).

Essas oscilações de área estão diretamente relacionadas às oscilações de preço do produto no mercado internacional. Figueiras et al (2009) aponta que quando há alta nos preços, os pipericultores tendem a aumentar área de colheita com intuito de produzirem mais e obterem maiores receitas.

Os dados referentes à produção brasileira de Piper nigrun de 2008 a 2017, nota-se que, a produção anual entre os anos de 2008 a 2014 obtiveram uma queda, porém é evidente que esse declínio foi mais acentuado entre os anos de 2011 a 2014 uma média 43151.5 toneladas, bem abaixo dos anos de 2008 com 69600 (t) e 2017 com quase 80000 (t). Observa-se o rendimento médio da produção em kg/ha, em análise em um intervalo de tempo de 10 anos, de 2008 a 2017, esses valores se mantiveram entre 2107 a $2385 \mathrm{~kg} / \mathrm{ha}$, já em 2017 houve um acréscimo, onde o rendimento médio foi de $2772 \mathrm{~kg} / \mathrm{ha}$.

No estado do Pará a área colhida tem diminuído. Mesmo sendo o maior estado produtor não é o que possui maior produtividade (IBGE, 2017). A quantidade produzida no estado também declinou no ano de 2017 a produção alcançou 39577 toneladas, comparado com ano de 2008 foram quase 16,5 mil toneladas a menos (uma queda de aproximadamente 29,32\%). Nota-se que o ano de 2014 obteve os menores valores de produção. 
Ao analisar as diferenças entre o início e o fim do período (2008-2017), observa-se que o efeito total foi negativo, resultante da diminuição da área colhida de 24654 ha para 16139 há (aproximadamente 34,54\%).

Entre os municípios do estado os principais produtores quanto à quantidade produzida em toneladas estão Tomé-Açu, Igarapé-Açu, Capitão Poço e Baião (SEDAP, 2017). Silva et al. (2017) apontam que dentre as mesorregiões paraense o nordeste do estado se destaca com a maior produção, como $87 \%$ de toda a produção estadual, apontando, deste modo, a importância da mesorregião no cenário produtivo de pipericultura.

O cultivo se dá principalmente pelo sistema de monocultivo, entretanto em Tomé-Açu, novas formas de produção estão sendo empregada ao cultivo da pimenta-do-reino, um dos diferenciais da produção é o plantio consorciado em sistemas agroflorestais (SAF’s).

\section{CONCLUSÕES}

Apesar das oscilações de área destinada à colheita, área colhida e produção de pimentado-reino no período mencionado, 2008-2017, o Brasil ainda apresenta um percentual elevado de produção encontrando-se entre os cinco maiores produtores de pimenta-do-reino do mundo.

O Estado do Pará é um grande produtor nacional com destaque por vários anos principalmente pela utilização de sistemas agroflorestais na cidade de Tomé-Açu, se tornando referência nacional. Contudo, por falta de técnicas inovadoras, fatores econômicos de mercado interno e externo, bem como, falta de políticas públicas que possam corroborar com a produção, estes fatores afetam diretamente a produtividade, evidenciando deste modo, as acentuadas oscilações.

\section{PRINCIPAIS REFERÊNCIAS}

CARNEIRO JUNIOR, J. F. C.; LIMA, J. M. de; SILVA, A. L. P. da; NASCIMENTO, M. de N. C. Ferreira. Análise de mercado da pimenta-do-reino no período de 1990 a 2015. Tecnologia \& Ciência Agropecuária, João P Análise de mercado da pimenta-do-reino no período de 1990 a 2015essoa, v.11, n. 6, p. $139-145,2017$.

FILGUEIRAS, G. C.; HOMMA, A. K. O.; SANTOS, M. A. S.. Conjuntura do mercado da pimentado-reino no Brasil e no mundo. In: Embrapa Amazônia Oriental-Artigo em anais de congresso (ALICE). In:

GAIA, J.; MOTA, M. G.; DERBYSHIRE, M. T. V.; OLIVEIRA, V. R.; COSTA, M. R.; MARTINS, C. D. S.; POLTRONIERI, M. C.. Caracterização de acessos de pimenta-do-reino com base em sistemas enzimáticos. Horticultura Brasileira, Caracterização de acessos de pimenta-do-reino com base em sistemas enzimáticos Brasília, v. 25, n. 3, p. 333-342, 2007. 
GIL, A. C.. Como elaborar projetos de pesquisa. 6. ed. - São Paulo: Atlas, 2018.

GOMES FILHO, J.; SANTOS, E. B. dos S.; AMORIM, E. P. da R.. Controle da fusariose (Fusarium solani f. sp. piperis) em pimenta-do-reino cv. Bragantina com extratos brutos aquosos e fungicida. Summa phytopathol, Botucatu, v. 46, n. 1, p. 49-52, Jan. 2020.

HOMMA, A. K. O. Extrativismo, biodiversidade e biopirataria na Amazônia. Brasília DF, Embrapa Informação Tecnológica, 2008.

IBGE - INSTITUTO BRASILEIRO DE GEOGRAFIAE ESTATÍSTICA. Levantamento Sistemático da Produção Agrícola: Pesquisa mensal de previsão e acompanhamento das safras agrícolas no ano civil, 2017. Rio de Janeiro: IBGE, 2018.

IBGE - INSTITUTO BRASILEIRO DE GEOGRAFIA E ESTATÍSTICA. Produção Agrícola nacional e regional. Rio de Janeiro: IBGE, 2017. Disponível em: https://sidra.ibge.gov.br/tabela/1613 . Acesso em: 20 maio de 2021.

IBGE - INSTITUTO BRASILEIRO DE GEOGRAFIA E ESTATÍSTICA. Produção Agrícola Municipal 2018. Rio de Janeiro: IBGE, 2019.

SEDAP - Secretaria do Desenvolvimento da agropecuária e da Pesca. Panorama agrícola do Pará - Pimenta-do-reino. Governo do Estado do Pará, 2017. Disponível em: http://www.sedap.pa.gov.br/ content/pimenta-do-reino Acesso em: 21 de maio de 2021.

SILVA, F. dos S.; BENTES, M. H. de V.; PENA, H. W. A. Modelagem de exportação da pimenta-doreino no estado do Pará entre 2000 e 2014, Amazônia, Brasil. Observatório de lá Economía Latinoamericana. Revista Eumednet. Enero 2016.

SILVA, L. do R.; LIMA, L. F. de; SOUZA, L. do S. F.; PEREIRA, B. W. de; VIANA, R. G. Conjuntura do mercado da pimenta-do-reino no Pará. I Conjuntura do mercado da pimenta-do-reino no Pará In: CONGRESSO INTERNACIONAL DAS CIÊNCIAS AGRÁRIAS, IV, 2017, Natal. Anais...Natal: COINTER - PDVAgro, 2017. 